\title{
Contemporary China Designs Education Binary Contradiction in the Context of the Consumer Society*
}

\author{
Hao Huang \\ College of Teachers \\ Chengdu University \\ Chengdu, China 610106
}

\author{
Zhengbo Zhang \\ College of Chinese and ASEAN Arts \\ Chengdu University \\ Chengdu, China 610106
}

\author{
Lianlian Gao \\ College of Chinese and ASEAN Arts \\ Chengdu University \\ Chengdu, China 610106
}

\begin{abstract}
Currently, there are four prominent "binary contradictions" in design education in China, namely the contradiction between the popular education policy and the demand for high-end design talent, the contradiction between the technical design talents and the general demand of social production, the contradiction between the design talents supply structure and the demand of the basic industries as well as the contradiction between traditional handicraft inheritance and modern design education pattern. The popular education policy has trained thousands of skilled design talents and delivered much-needed design talents to China's industrial development. However, after the industrial age and in the modernity society, on the one hand, ford socialist concept of talent training can't well satisfy the consumer society demand for high-level designers. On the other hand, with the concept of industry 4.0, China's basic industrial design talent shortage will not be able to support "made in China 2025" strategy deployment and industrial intensive transformation and upgrading. In addition, the growing gap between traditional handicraft inheritance and the modern "westernization" design education model may exacerbate some traditional cultural disappearance. Therefore, the China design education concept, system, model and strategy should keep pace with the times and actively make exploration and innovation.
\end{abstract}

Keywords-consumer society; China design education; binary contradictions; innovation to upgrade

\section{INTRODUCTION}

According to statistics, in 2015, China added more than 4 trillion RMB in savings deposits and more than $\$ 50$ trillion in savings, second only to Qatar and Kuwait, which ranked third in the world. The annual average consumption of

*This article is a phased achievement of the graduate education project of Chengdu University: "Research on the Innovative Application of Extracurricular Unconscious Education Theory in the Reform of the Comprehensive Quality Training Mode of Art Graduates" (Number: cdjgy2017028) residents is $19,308 \mathrm{RMB}$, and the contribution of consumer spending to GDP is $60.9 \%$. Consumption has become the main driving force for China's economic growth, which has entered a period of rising consumption experience. Referring to the evolution of western industrial society, in the $1960 \mathrm{~s}$ west already enter (Baudrillard) consumption age, go to "surplus economy" and "leisure class" (Bollen) is a remarkable feature of late capitalism society (Jameson). "In this context, culture and art and aesthetic experience as the tool of making consumer desire is naturally, into the economic system of a consumer society, aestheticism and consumerism confluence becomes a systematic" [1]. As a result, the modern Design Education (the Design Education) is also put forward higher request, reversed transmission the renewal Education idea, the innovation Education pattern, in order to cultivate advanced, with Chinese culture and mark Design talents. At present, there are many binary contradictions in the design of education and social design talents in China.

\section{POPUlar EdUCATION POLICY AND HIGH-END DESIGN TALENT DEMAND CONTRADICTION}

In the 1980s, Deng Xiaoping put forward "Three faces of education", issued by the central "decision on reform of the education system of the central committee of the communist party of China, the ministry of education issued" China education reform and development compendium" and other policies and regulations, advocate" expand agricultural secondary schools, all kinds of secondary vocational schools, vocational school in higher education structure in the proportion of... Develop professional technology education. In the late 1990s, the education, a mid-range professional design school and advanced design art, expanded rapidly, and China gradually became the largest country in the world to design education. At the beginning of the 21 st century," the Chinese art design professional undergraduate course and 
specialized subject of colleges and universities has reached more than 1400, the number of graduates each year more than about 10, design art has become China's third largest after computer and English majors in colleges and universities professional." [3]

According to the Guangzhou academy of fine Professor Tong HuiMing research team found that "every year there are about 150000 of obtain employment of personnel of design team, has turned in a quarter of a century of China by not a small modern design education was emerged as the world's leading design education power. Assuming that can maintain the education scale, and students can continue to work in their own professional, after graduation means that by 2050, nearly 7 million of China's 1.6 billion people will work in the position of stylist."[4] Under the influence of popular education policy, gradually formed the current China's big design professional colleges and universities generally implement standardized "copy" type education mechanism, the design team, better meet the needs of the rapid development of labor-intensive industries, provides the public with affordable products and services, make the social from all walks of life to enjoy to the Bauhaus style and mechanical characteristics of aesthetics as the leading function.

But as the cultural creative industry rapid rise in consumption value specifications and high quality social modernity of aesthetic subjectivity demands, people began to call for the original design masters, such as in the field of public building design master Le Corbusier, Tadao Ando, Bei Yuming, Kengo Kuma research and design master Siemens in the field of furniture products, mark newsom, Naoto Fukasawa, and the Kenya Hara, master the design different from traditional mechanic, they not only understand the consumer psychology, to create beauty and symbolic significance (authority), identity and status of goods, also can create a new way of life for the mechanical stiffness of the norm of life into a new feeling, accurately grasp the pulse times lead fashion consumption globalization trend. Of course, such designers are not solely dependent on education, but there are also differences in creative endowments. But in terms of China's design education system, and should be under the standardized education training mode, to personalized, elite talent training paradigm transformation, and provide good education for Chinese design master's ecological environment.

\section{The CONTRAdiction BetweEn THE SKILlED DESIGN TALENT AND THE COMPREHENSIVE DEMAND OF SOCIAL PRODUCTION}

There is a long-running debate over the design of education, which is that design should belong to engineering or art-centric arts. Wang Shouzhi thinks "because the scope of the design is very complex, so impossible to have a unified design range, and can only according to the different design of the specific situation to determine its properties. Because of the close relationship with engineering technology, industrial production should be oriented towards engineering. Graphic design, packaging design, advertising design, interior design are more distant from the engineering technology, and the sensitive performance of aesthetic perception is closely related, so it is natural that it is biased towards fine arts. [5] In fact, no matter how to define the scope of design disciplines, for design talented person, should strengthen the design and other related disciplines, cross training, to improve their knowledge structure, improve their comprehensive quality. For example, for industria design talents, strengthen the study of consumer behavior and psychology, design ethics, design aesthetics, marketing, etc. For the design of graphic design, packaging design and other design, it is more closely related to the design, and strengthens its literature, history and philosophy. Otherwise, cultivate only can call the mechanic design, is engaged in technical workers in a certain area, and can't rise to the height of the designers, omnipotent designer soul, also cannot meet the high quality of consumer society cultural, the aesthetic demand. Such as, we can produce all kinds of function of mobile phone, can also meet the requirements of consumers to look beautiful, but it is difficult to create the iphone symbolic significance and international brand influence. Some design institutions have actively explored this direction, but in general, there are still more skilled design talents in the market, and there is a large gap between the social needs of the complex talents.

It mainly displays in: (1) in terms of creative quality, skilled talents stay mostly in Photoshop, AI, Flash, skill level and so on $3 \mathrm{dmax}$, such as visual artists, voice processing, and animation, but lack of literature, society, history, philosophy, anthropology and other disciplines of widely, the resulting design ideas, the lack of humanistic spirit. (2) in terms of consumption experience, skilled talents mostly can draw flush, design model, but the lack of insight into the consciousness of market changes, to capture consumer demand, the lack of design oriented pull production, marketing ability, constantly repeating "behind closed doors" type mechanical action. (3) in terms of international influence, and persons with almost no major design projects and awards at home and abroad, such as the national grand theatre, the bird's nest stadium, the Olympic water cube and CCTV main building projects and the IF, IDEA, red dot, Pulitzer basic by foreign designers won international awards, such as the occasional won the international competition of Chinese designer, has failed to scale effect. Therefore, Chinese design education should abandon the purely utilitarian thinking skills training, enhance the interdisciplinary between joint cultivation, the introduction of "production, study and research, use" the cultivation of the multi-agent interaction, coordination mechanism, to explore the inter-disciplinary talent hatch general, effective and feasible way.

\section{Design Talent SuPply Structure AND BASIC INDUSTRY POSITION DEMAND CONTRADICTION}

According to the Boston consulting group, the American economy and the China economic news and other comprehensive survey data show: "Chinese designer main distribution industry: architecture design, interior design, industrial design, fashion design, product design, graphic design, website design and so on seven categories. With the 
rise of smart devices, robots, the Internet of things, and the rapid development of the Internet, the demand for quality of life has been greatly improved and personalized. In the next five years, especially in the industrial design, environmental design, product design niche, there will be huge talent gap requirements, will usher in the next design demand peak." But in terms of the proportion of Chinese designers' major distribution, only about $10 \%$ of them are engaged in industry (machinery, transportation, communication equipment, etc.) and architecture design.

This is mainly because: (1) there are relatively few industrial designers in China. According to the Guangzhou academy of fine TongHuiMing professor team survey data show: "2007, 321 schools across the country have professional industrial design students, if these colleges and universities recruit students of 30 students each year, 4 years ownership in 120, a rough calculation on the industrial design major students about 38520, there are about 9630 students each year graduate jobs took to the society." [6] (2) graduates are less likely to enter the manufacturing sector. "The Chinese culture of hundreds of thousands of design graduates each year, most of the jobs in advertising, packaging, graphic design, etc to decorate beautification services industry, really into the manufacturing is rare. As a result, China's urban construction and the environment has become a ocean of ads, signs, posters, and large scale and demand more pressing manufacturing (cars, home appliances, furniture, clothing, digital media, etc.) because of the lack of their own design masters, and few national brands. China's manufacturing industry has become a well-known western brand processing and manufacturing enterprise. [7]

Therefore, the existing designers supply far cannot meet the demand of basic industry position, the second industry industry (manufacturing, electric power, mining, military industrial chemical industry and construction industry, etc.) not configured enough designers. "Made in China 2025" national strategy implementation, need similar Yu Beilun, Raymond lowe, sottsass four people group, Siemens, Memphis and black sichuan, sori yanagi, or more handsome, deep ze straight and other famous industrial designer's talent pool, if the depth of the lack of industrial designers involved, it is hard to imagine that the "made in China" to "Chinese intellectual" and " design by China " the success of the transformation.

\section{TRADITIONAL HANDICRAFT INHERITANCE AND MODERN DESIGN EDUCATION MODE CONTRADICTION}

Today, handcrafted handicrafts from all over the world are becoming more and more popular among fashion consumers, and many have become a low-profile luxury. Such as Rolls Royce, Pelikan Baili pen, Lang\&Heyne Lang Heine watch, KPM Berlin (ceramics), Burmester (sound reproduction), Schramm Werkstatten (household) etc. The reason is that it,s hard to build the emotional charm that the production of water chemical industry can produce by hand. The former does not emphasize the economic efficiency and quantity of engineering thinking, but emphasizes the physical characteristics of the objects and the craftsman's essence of life. The quality of this material is in stark contrast to the aesthetic of the goods that the high-tech capital society produces during the Internet era. So, that,s for them to win consumers and worship identity created a not allow to copy the core competitiveness, at the same time, also for countries to the weakening of traditional handicraft recovery provides a valuable market opportunities.

Back at itself, "in the early $1980 \mathrm{~s}$, China has introduced" the Bauhaus "and the western modern design education mode, but the 'introduction' doesn't really cut to the manufacturing industry and the economic system of the deep, just floating in the surface layer of form imitation form."[8] In the process of excessive promoting western modern design education, lack of the thought of Chinese traditional culture and traditional arts and crafts tradition consciousness. We often heard: "national character" is more like a slogan and the lack of substantial contents, the public still reckless with Europe and the United States or East Asian consumer culture, aesthetic consciousness. In the context of this cultural invasion, the traditional aesthetic system of the country has been gradually watered down.[9] In addition, the great leap forward, the cultural revolution, such as social unrest, make our traditional crafts in succession developing suffered varying degrees of hinder, gradually lost their personality at the same time, missed a historic opportunity for many times.

"Renaissance in early design movement in the west, their craft for the purpose, and in the modernization and industrialization, artists began to accept industrialization and modern science result in art and design."[10] That is, all the modernization, industrialization and urbanization of country will face the dilemma, Britain, France, Germany, Italy, Japan and other developed countries has been and continues to experience a painful process, we are also unable to avoid. To this end, we need to consciously change for the traditional "contempt of craft, make great craftsman not free the mind and body free up" (Hangjian), to explore from resolving the conflicts endogenous handicraft and industrial standardization development, and then find the reconciliation between craftsmanship and flow operation path of universal validity of division. The path of reconciliation that has been passed by developed countries such as Germany, Italy and Japan may have implications for us.

Germany protected the decline by using primitive manual manufacturing and legal systems. The German government is trying to explore traditional crafts and modern life concept, in the process of the balance between modern society demand, in the world's last remaining leather gloves manufacturers Roeckl, The oldest pencil maker in Europe, faber-castell. Tens of thousands of small businesses or family enterprise endogenous "spirit" will be able to pass on. Italy to dissolve the handicraft of inheritance and internal conflict of modern industrial development, take the lead in implementation of double-track, let the national arts and crafts and industrialized mass production and axle development: for export service of large enterprises to adopt large-scale mechanization production means; For the domestic service small-scale workshop production quality, small batch handicraft products. Under the dual regulation education mode, they value both the standardized training of 
design and the inheritance of handicraft training under the master mode. Thus, their design talents have both highly rational industrial standard practice and strong personality. Late 50s, Japan in the following, draw lessons from, imitating Germany, Italy and the United States on the road of development, formed the same manual tradition and the modern design education dual-track parallel development pattern. Japan will foster implements in the field of traditional craft exquisite workmanship and pious attitude into product design and manufacturing, in material, chemical industry, precision machinery, precision measurement, instrument, electronics and other industrial areas, to can't simulate precision technology and craft technology, unique products to establish fine, fine, special and deeply, formed the typical Japanese style. Then, in view of such as gardening, pottery, embroidery, paper cutting, thus unique characteristics of the Chinese traditional arts and crafts, in addition to a large number of experts and scholars and the protection and inheritance of folk organization, called for a policy for the protection of intangible cultural heritage and promote handmade into daily consumption market, whether the Chinese design education system should be the introduction of the concept of "western" at the same time, positive thinking? We should Establish the corresponding training mode and inheritance mechanism, combine the inheritance system of handicraft master and modern education to ensure the effective inheritance and innovation development of traditional handicraft.

\section{CONCLUSION}

Since Reform and Opening up, in Marxist theory of literature and art, under the guidance of Deng Xiaoping's education thought of "three facing", contemporary Chinese design education in the social production practices, research and development-production-consumption) and theory of development, has achieved fruitful results. However, with the coming of post-industrial era and the modern consumer society, the contemporary Chinese design education idea, education policy and education mode with the time development needs, such as between the inevitable "dual conflicts", this is the inevitable outcome of the development of modern education. This requests us in the introduction of the concept of "western" design education at the same time, combined with China's consumer culture, the industrial transformation and upgrading, the national brand promotion and traditional arts and crafts tradition for design talented person's demand, improve the design education system with Chinese characteristics, for high-end, the composite design master provide good education environment.

\section{REFERENCES}

[1] Yu Hong. Art and Home[M]. China Renmin University Press, 2005, preface.

[2] Wang Changchun. Four Waves of China's Education Reform from 1979 to 2002[J]. Journal of Capital Normal University, 2002(4):103.

[3] Hou Shuangshuang. The lack of divine aesthetics in the contemporary Chinese art design education system[J]. Art ocean, 2014(11):137.

[4] Education Ministry. Statistical Bulletin of the National Education Development in 2010 [N]. China Education News, 2011(7).
[5] Wang Shouzhi. World modern design history[M]. China Youth Publishing Press, 2015.p28.

[6] Tong Huiming. The contemporary crisis of Chinese design education[J]. Decoration, 2008(4):57.

[7] Zhao Xin. Reflections on Chinese Contemporary Art Design Education[J]. Journal of Zhengzhou University of Light Industry, 2007(4):6.

[8] Peng Liang. The status quo and problems of design education in manufacturing countries[J]. Design education, 2007(5):96.

[9] Liu Guanzhong. Take the road of Chinese contemporary industrial design[M]. Hunan Science and Technology Press, 2004. preface.

[10] Zong Heng. Looking at the issue of contemporary design education from the formation of Chinese art design[J]. Fine art view, 2012(2):178 